\title{
Analysis of Influence Factors of Pore Water Pressure Change in Frozen Soil
}

\author{
Kun Zhang $\mathbb{D}^{1}$ and Lianhai Zhang $\mathbb{D}^{2}$ \\ ${ }^{1}$ Gansu Transportation Research Institute Group Co.,Ltd., Lanzhou 730000, China \\ ${ }^{2}$ State Key Laboratory of Frozen Soil Engineering, Chinese Academy of Sciences, Lanzhou 730000, China \\ Correspondence should be addressed to Lianhai Zhang; zhanglh@lzb.ac.cn
}

Received 22 April 2021; Accepted 9 June 2021; Published 19 June 2021

Academic Editor: Hao Zheng

Copyright (c) 2021 Kun Zhang and Lianhai Zhang. This is an open access article distributed under the Creative Commons Attribution License, which permits unrestricted use, distribution, and reproduction in any medium, provided the original work is properly cited.

\begin{abstract}
In this article, changes of pore water pressures (PWP) in silty clay subjected to freezing and thawing were measured under an open-system condition. A total of five soil samples were tested, with water contents of $10.70 \%, 18.28 \%, 23.98 \%, 31.00 \%$, and $37.65 \%$, respectively. Each experienced a first-step freezing stage, a thawing stage, and a second-step freezing stage. The results showed that changes in PWP depended on the water content, soil type, salinity, ice content, air, pressure, temperature, and others. The PWP minimum with initial water content has a " $\mathrm{w}$-shaped double-valley" characteristic, which described two PWP minima existing in two optimum water contents as initial water content increased. An influence-factor analysis of PWP was proposed and gave a reasonable interpretation on the "w-shaped double-valley" characteristic of PWP. In addition, the tensiometer method to measure PWP in frozen soil was further discussed with regard to its advantages and disadvantages.
\end{abstract}

\section{Introduction}

Construction and operation in cold regions may encounter many environmental and engineering problems, such as permafrost degradation, frost heaving, icing, thaw settlement, thermokarst, and infrastructure failure. With the development of our country's economy and implementation of Western development strategy, increasing projects are built in cold regions, including railway, highway, power transmission line, and petroleum pipeline. Therefore, increasing research work begins to focus on the deformation process of frozen soil involving construction of these projects. Frost heave and thaw settlement are two uppermost hazards generally causing significant damages during engineering construction and operation, and accurate prediction of the deformation process is an important issue that needs to be urgently solved.

Water migration and ice segregation as two essential issues of the frost heave and thaw settlement problem have always been of interest to researchers $[1,2]$. When soils are subjected to freezing, soil water freezes in situ with volume increasing of $9 \%$, or freezes in ice segregation way with volume increasing of $109 \%$. During ice segregation, water migration occurs. Numerous investigations have focused on the mechanisms of water migration and ice segregation, and many theories and models have been proposed and studied, including primary heaving theory [3-5], second heaving theory [6-8], and segregation potential theory $[9,10]$. Moreover, PWP measurement in freezing soil has been an essential and key research work for further exploring the mechanisms of water migration and ice segregation [11].

However, most of investigations on PWP were empirical speculations or model calculations without direct experiment data support. The measurement method of PWP has been a challenge; only little work was focused on this research, including hygrometer method [12], axis-translation technique [13-15], Pf-meter method [16], and tensiometer method [17-21]. Recently, increasing attention began to focus on the tensiometer method. Zhang et al. [22] gave a further improvement to this method based on previous investigations on the measurement of PWP during soil freezing. Using the novel PWP gauge, the PWP of sandy soil 
was measured in laboratory [22]. Based on the testing results, a change mode of PWP was suggested, and then the frozen fringe process is analyzed, including the consolidation of unfrozen zone, ice segregation, water migration, the applicability of the generalized Clausius-Clapeyron equation (GCCE), and phase transition [23]. In addition, soil type is a key influence factor for the frost heave and thaw settlement deformation, and water migration and ice segregation are more likely to occur in the frost-susceptible soils. Therefore, compared to sandy soil, silty clay as a frostsusceptible soil is more helpful to reveal the behaviors of water migration and ice segregation.

Herein, we performed a series of PWP measurements on silty clay subjected to freezing and thawing, and then a detailed analysis on influence factors of the PWP is presented, which will favor a further understanding of phase change processing of soil water during soil freezing and thawing.

\section{Materials and Methods}

2.1. Sample Preparation. Silty clay as a typical type of soil along the Qinghai-Tibet railway was tested, and the grain size distribution and Atterberg limit of this soil are shown in Table 1. The soil samples were prepared and tested at the State Key Laboratory of Frozen Soil Engineering in Lanzhou, China. The soil was thoroughly mixed with certain water content and then hammered by a plane hammer into a cylindrical Perspex cell. Therefore, each soil sample had a diameter of $101 \mathrm{~mm}$. A total of five soil samples were prepared and measured during the experiments. The water content of samples CN1, CN2, CN3, CN4, and CN5, respectively, were $10.70 \%, 18.28 \%, 23.98 \%, 31.00 \%$, and $37.65 \%$. Other specific soil sample parameters, such as the initial water content and height, are shown in Table 2.

2.2. Testing Program and Condition. The cylindrical Perspex cell packed with the tested soil sample was put into the box of the freeze-thaw cycling test machine. All of the temperature probes and porous ceramic cups of PWP gauges were inserted into the soil sample through the small holes in the wall of the cell. Figure 1 is the detailed probe arrangements on the cylindrical Perspex cell. The detailed sketch of freezethaw cycling test machine and the design of PWP probe refer to the article written by Zhang et al.[22]. Each sample experienced a process that included three stages: a first-step freezing stage (abbreviated as fre1), a thawing stage (thw), and a second-step freezing stage (fre2). Every step-freezing stage (fre1 or fre2) was also divided into three steps (abbreviated as I, II, and III) according to different top plate temperatures. In every step of the freezing stage (frel or fre2), the testing time is approximately 48 hours. In the thawing stage, soil sample thawed under room temperature with a time of approximately 24 hours. All temperature conditions of the samples tested are listed in Table 2. During testing, PWP, temperature, and water volume absorbed into soil sample were measured and recorded. After every test ended, the water content distribution of each sample was also obtained using gravimetric method.

\section{Results}

3.1. Water Migration Volume. Figure 2 is the variations of water volume absorbed into silty clay samples CN1, CN2, $\mathrm{CN} 3$, and CN4. As shown in Figure 2, the water volumes absorbed into samples have the characteristics as follows:

(1) During soil freezing, the water volumes absorbed into samples $\mathrm{CN} 1, \mathrm{CN} 2, \mathrm{CN} 3$, and $\mathrm{CN} 4$ linearly increased over time. This implied that increasing water was absorbed into samples during freezing.

(2) Samples with different water contents differed greatly in water volumes absorbed into the samples, and the water volumes absorbed into samples decreased as the initial water content increased. For example, as shown in Figure 2, after the same testing time (312 hours), the water volumes absorbed into samples $\mathrm{CN} 1, \mathrm{CN} 2, \mathrm{CN} 3$, and $\mathrm{CN} 4$ are approximately $471.87,309.60,379.52$, and $238.98 \mathrm{~cm}^{3}$, respectively. The average migration rates of water absorbed into samples are approximately 0.027 , $0.018,0.022$, and $0.014 \mathrm{~cm}^{3} / \mathrm{M}$.

(3) As the initial water content increased, sample in the early stage of freezing experienced a state transition from water absorption to drainage. For example, in the early stage of freezing (frel.I), water was absorbed into sample $\mathrm{CN} 1$ but squeezed out of samples $\mathrm{CN} 2, \mathrm{CN} 3$, and CN4. This state difference exactly explained why sample with lower initial water content had a larger water volume absorbed into it.

(4) In the thawing stage, except little water absorbed into the samples in the early stage of thawing, no water was absorbed into samples.

Figure 3 is the water content distributions of samples $\mathrm{CN} 1, \mathrm{CN} 2, \mathrm{CN} 3$, and $\mathrm{CN} 5$ at the end of each testing. As shown in Figure 3, we found the following:

(1) Water content of the bottom part of sample (the unfrozen zone) was smaller than that of the upper part of sample (the frozen zone), which implied that there exists water migration from the unfrozen zone to frozen zone.

(2) Water contents at the bottom part of all samples (the unfrozen zone) were smaller than the initial contents, which implied that there existed certain consolidation in the unfrozen zone.

3.2. Displacement of Soil Sample. Figure 4 is the variations of displacement of samples $\mathrm{CN} 1, \mathrm{CN} 2$, and $\mathrm{CN} 4$ during freezing and thawing. As shown in Figure 4, samples CN1, $\mathrm{CN} 2$, and $\mathrm{CN} 4$ differed greatly in displacement during freezing and thawing and presented some characteristics as follows:

(1) During soil freezing, there existed heaving of sample; the heaving displacement decreased as the water content increased; for each sample, the heaving displacement in the second freezing stage (fre2) was 
TABLe 1: Grain size distribution and Atterberg limits of soils tested.

\begin{tabular}{|c|c|c|c|c|c|c|c|c|c|}
\hline \multirow{2}{*}{ Soil type } & \multirow{2}{*}{ Liquid limit } & \multirow{2}{*}{ Plastic limit } & \multicolumn{7}{|c|}{ Particle size $(\mathrm{mm})$} \\
\hline & & & $<0.075$ & $0.075-0.1$ & $0.1-0.25$ & $0.25-0.5$ & $0.5-1.0$ & $1.0-2.0$ & $>2.0$ \\
\hline Silty clay (\%) & 25.5 & 11.9 & 19.83 & 51.90 & 17.0 & 7.43 & 2.90 & 0.47 & 0.0 \\
\hline
\end{tabular}

TABLE 2: Temperature conditions of soil samples tested.

\begin{tabular}{|c|c|c|c|c|c|c|c|}
\hline \multirow{3}{*}{ Samples } & \multirow{3}{*}{ Initial water content $(\%)$} & \multirow{3}{*}{ Height (mm) } & \multicolumn{5}{|c|}{ Temperature $\left({ }^{\circ} \mathrm{C}\right)$} \\
\hline & & & \multicolumn{2}{|c|}{ Fre1 } & & \multicolumn{2}{|c|}{ Fre2 } \\
\hline & & & $\begin{array}{l}\text { Top plate } \\
\text { (I/II/III) }\end{array}$ & $\begin{array}{c}\text { Bottom plate } \\
(\mathrm{I} / \mathrm{II} / \mathrm{III})\end{array}$ & thw & $\begin{array}{l}\text { Top plate } \\
\text { (I/II/III) }\end{array}$ & $\begin{array}{c}\text { Bottom plate } \\
(\mathrm{I} / \mathrm{II} / \mathrm{III})\end{array}$ \\
\hline $\mathrm{CN} 1$ & 10.70 & 112.3 & $-5 /-8 /-11$ & 1.5 & & $-3 /-5 /-11$ & 1.5 \\
\hline $\mathrm{CN} 2$ & 18.28 & 107.0 & $-11 /-14 /-17$ & 1.0 & & $-5 /-9 /-12$ & 3.0 \\
\hline $\mathrm{CN} 3$ & 23.98 & 121.0 & $-3 /-7 /-14$ & 3.0 & $R$ & $-3 /-7 /-14$ & 3.0 \\
\hline $\mathrm{CN} 4$ & 31.00 & 121.0 & $-3 /-7 /-11$ & 3.0 & & $-3 /-7 /-11$ & 3.0 \\
\hline CN5 & 37.65 & 125.0 & $-5 /-10 /-15$ & 1.0 & & $-5 /-10 /-15$ & 1.0 \\
\hline
\end{tabular}

$* \mathrm{R}$ denotes room temperature.

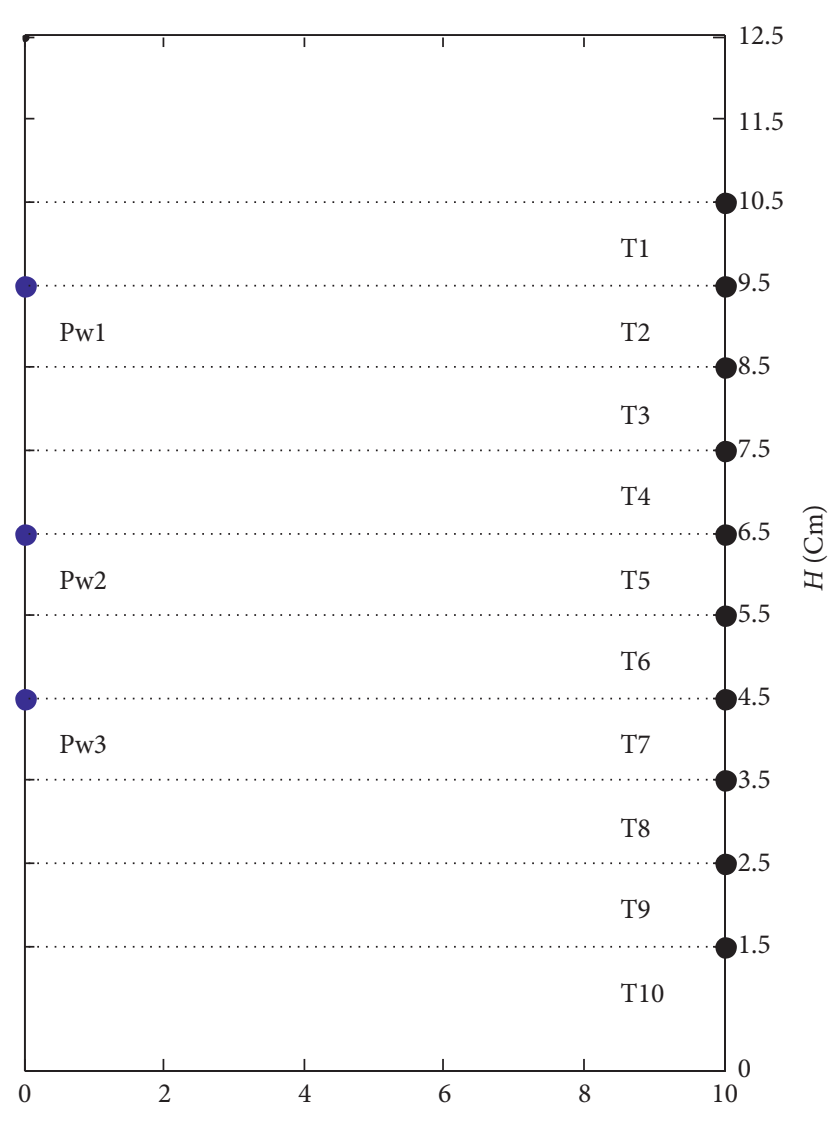

Hole

Figure 1: Probe arrangement on the cylindrical perspex cell. Pw1, Pw2, and Pw3 for pore water pressure probes; T1-T10 for temperature probes.

larger than that in the first freezing stage (fre1). For example, in the first freezing stage (fre1), the heaving of samples $\mathrm{CN} 1, \mathrm{CN} 2$, and $\mathrm{CN} 4$ is approximately $4.38,1.80$, and $1.79 \mathrm{~mm}$, respectively; in the second freezing stage (fre2), the heaving of samples $\mathrm{CN} 1$, $\mathrm{CN} 2$, and $\mathrm{CN} 4$ is approximately $5.79,2.20$, and $3.92 \mathrm{~mm}$, respectively. During soil freezing, the measured displacement, actually, is a sum of deformations of the frozen zone and the unfrozen zone. The deformation of the frozen zone was induced by a frost heave process, which generally induced the surface lifting. However, the deformation of the unfrozen zone might be induced by two different processes according to water content. When water content was large, the unfrozen zone mainly experienced a consolidation process, which generally induced the surface collapse. Conversely, when water content was low, the unfrozen zone mainly experienced an expanding process because some water was absorbed into this zone from the reservoir bottle, which generally induced the surface lifting. Therefore, the surface lifting decreased as the water content increased. However, the heaving displacements in the second freezing stage (fre2) were larger than those in the first freezing stage (fre1), which may be attributed to the fact that the displacements induced by consolidation in the second freezing stage (fre2) are smaller, compared to those in the first freezing stage (frel).

(2) During soil thawing, there existed settlement in all of samples; the settlement increased as the water content increased. For example, the thawing of samples $\mathrm{CN} 1$, $\mathrm{CN} 2$, and $\mathrm{CN} 4$ is approximately $0.55,1.65$, and $9.49 \mathrm{~mm}$, respectively. This thawing settlement is mainly ascribed to the consolidation and frost heaving during freezing which are both increase with water contents increase. Therefore, the settlement increased as the water content increased during thawing.

3.3. PWPs during Soil Freezing and Thawing. Figures 5-9 are the variations of PWP of samples $\mathrm{CN} 1, \mathrm{CN} 2, \mathrm{CN} 3, \mathrm{CN} 4$, and CN5 during the freezing and thawing. As shown in 


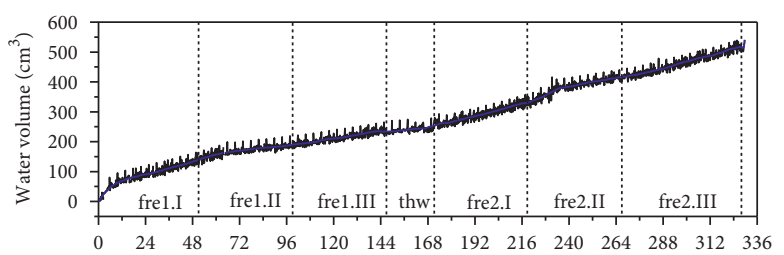

Time (hour)

- Water volume for $\mathrm{CN} 1$

50 pts AAv smooth of "water volume"

(a)

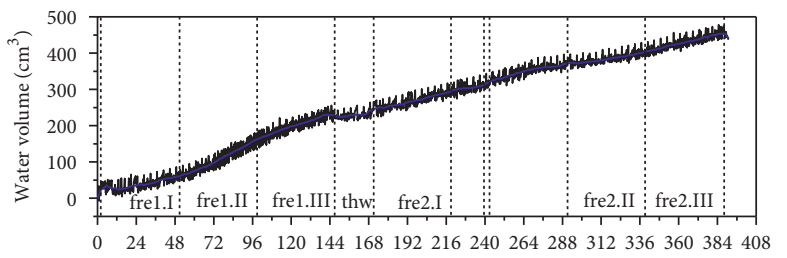

Time (hour)

—_ Water volume for $\mathrm{CN}_{3}$

50 pts AAv smooth of "water volume"

(c)

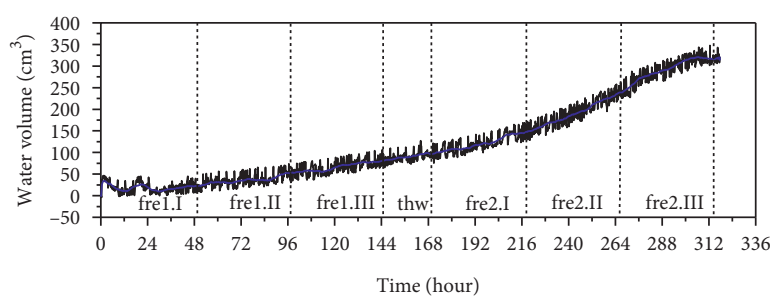

Water volume for $\mathrm{CN} 2$

_ـ 50 pts A Av smooth of "water volume"

(b)

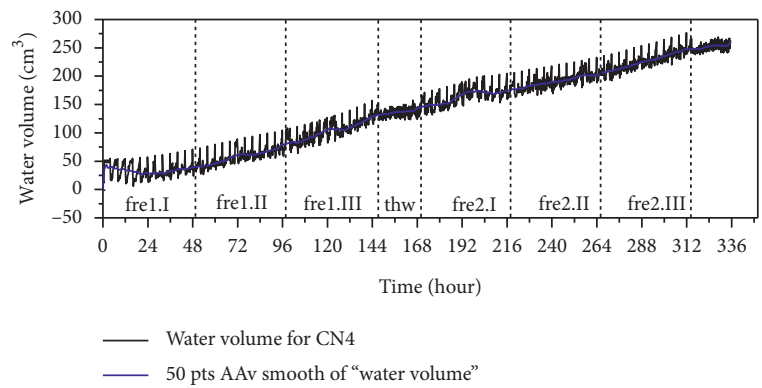

(d)

FIGURE 2: Variations of water volume absorbed into silty clay samples CN1, CN2, CN3, and CN4.

$\begin{array}{lllllll}5 & 10 & 15 & 20 & 25 & 30 & 35\end{array}$

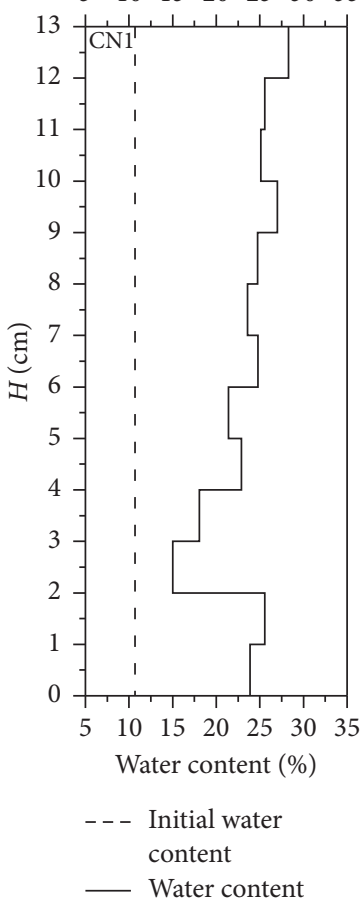

(a)
1214161820222426

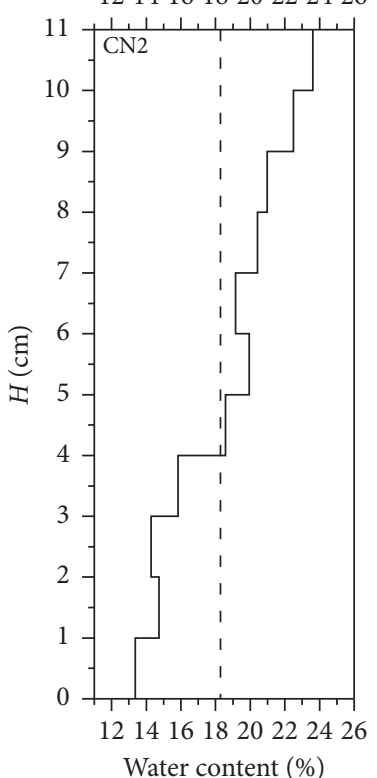

- - - Initial water content

Water content

(b) $\begin{array}{lllllll}10 & 15 & 20 & 25 & 30 & 35 & 40\end{array}$

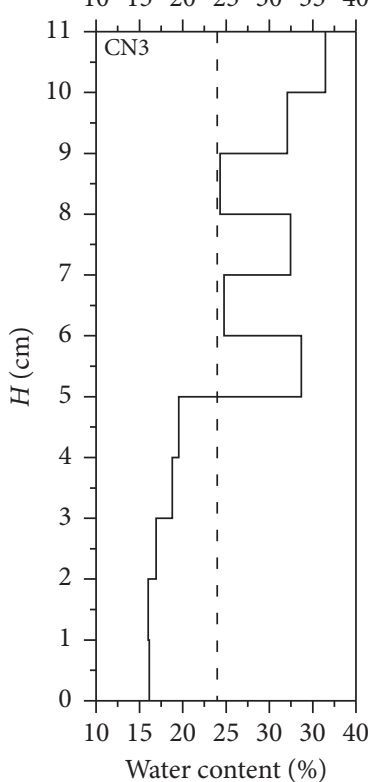

- - - Initial water content

- Water content

(c)
$0 \quad 10203040506070$

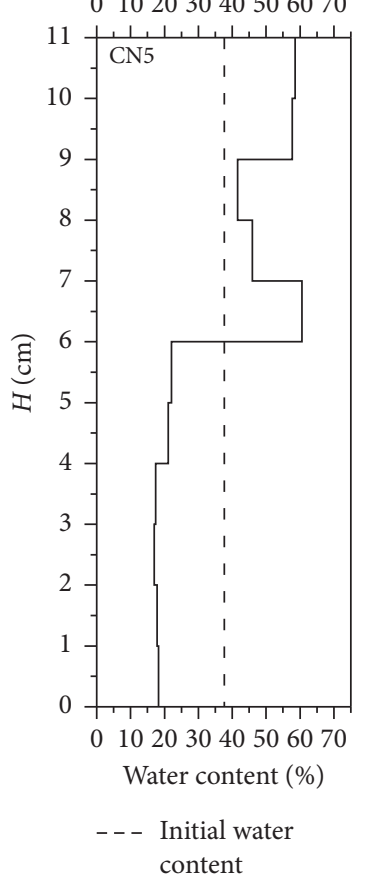

- Water content

(d)

Figure 3: Water content distributions of samples CN1, CN2, CN3, and CN5 at the end of tests. 


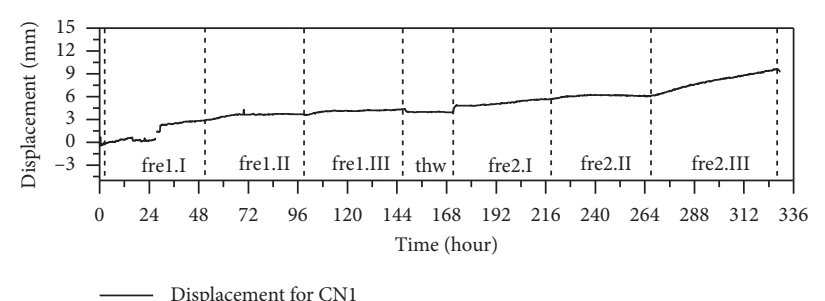

(a)

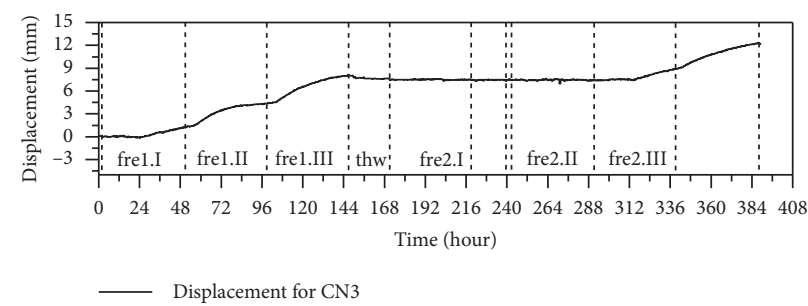

(c)

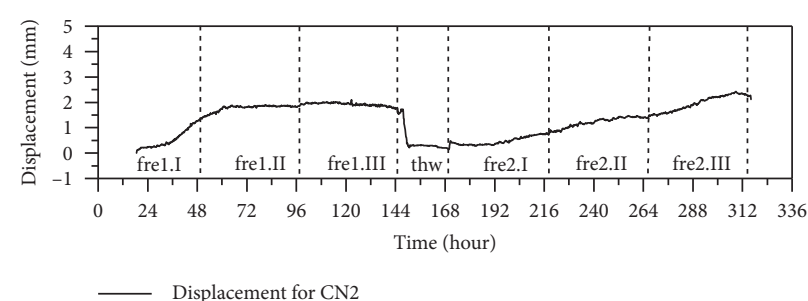

(b)

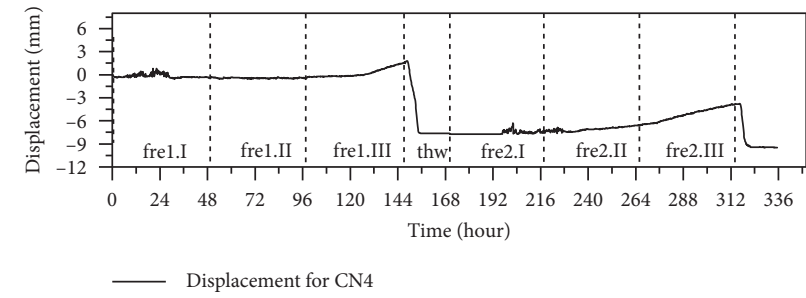

(d)

Figure 4: Variations in displacement of samples CN1, CN2, CN3, and CN4 during freezing and thawing.

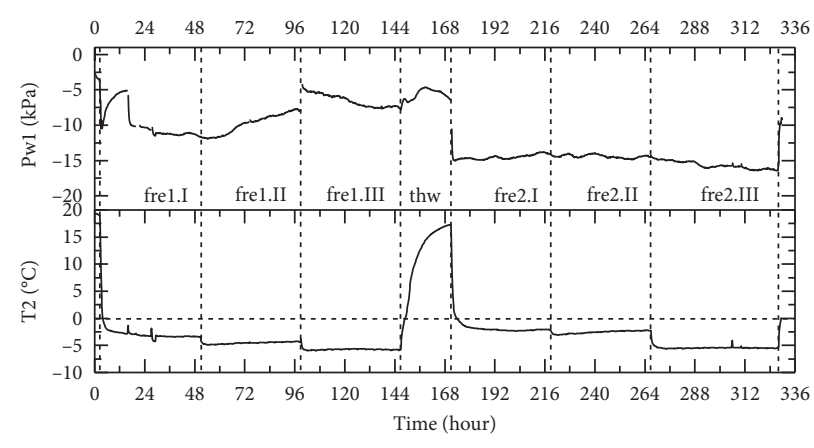

(a)

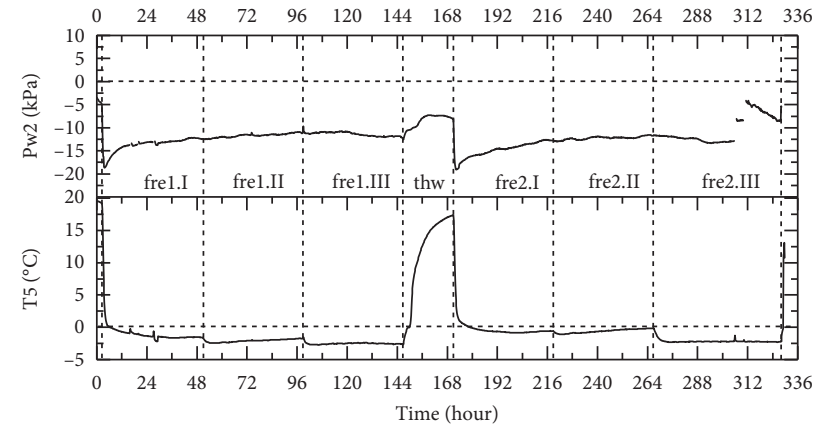

(b)

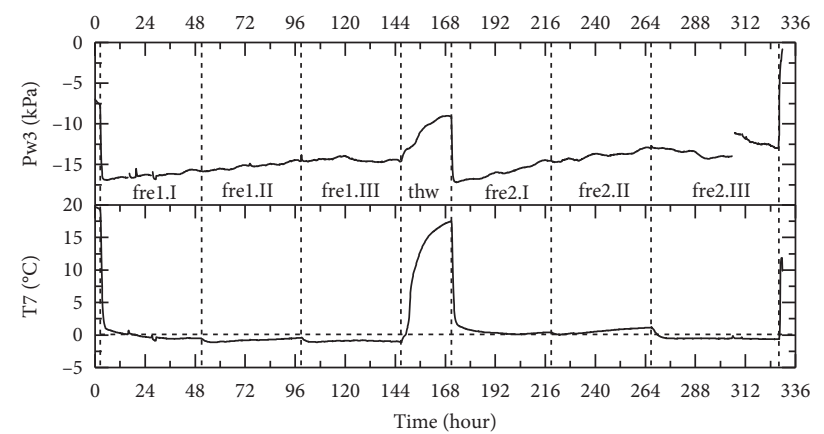

(c)

FIgURE 5: (a) Variation in the pore water pressure Pw1 and temperature T2 during the freezing and thawing of sample CN1. (b) Variation in the pore water pressure Pw2 and temperature T5 during the freezing and thawing of sample CN1. (c) Variation in the pore water pressure Pw3 and temperature T7 during the freezing and thawing of sample CN1.

Figure 5-9, we found some characteristics in the PWP as follows:

(1) During soil freezing, PWP decreased as temperature decreased. However, PWP in sample with low water content was less sensitive to the temperature change.

(2) During soil thawing, PWP increased as temperature increased.
(3) During soil freezing, the drop of PWP increased as the soil depth increased.

(4) The minimum of PWP with initial water content had a "w-shaped double-valley" characteristic, which described that two minima of PWP exist in two different water contents as initial content increased. Table 3 is the minima of PWP during every freezing 


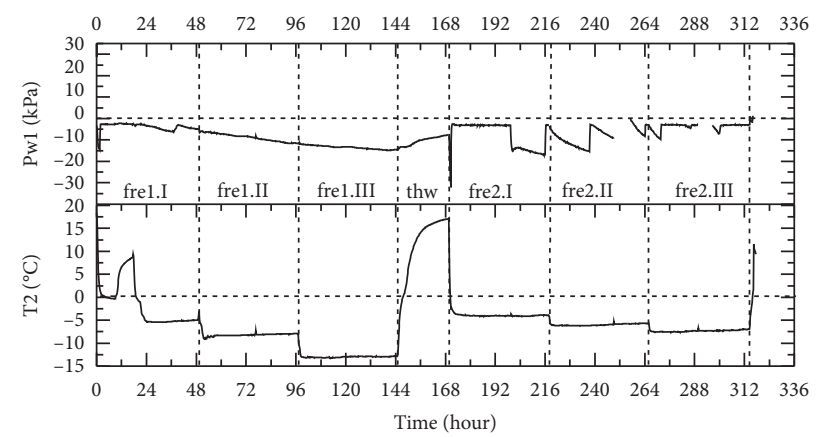

(a)

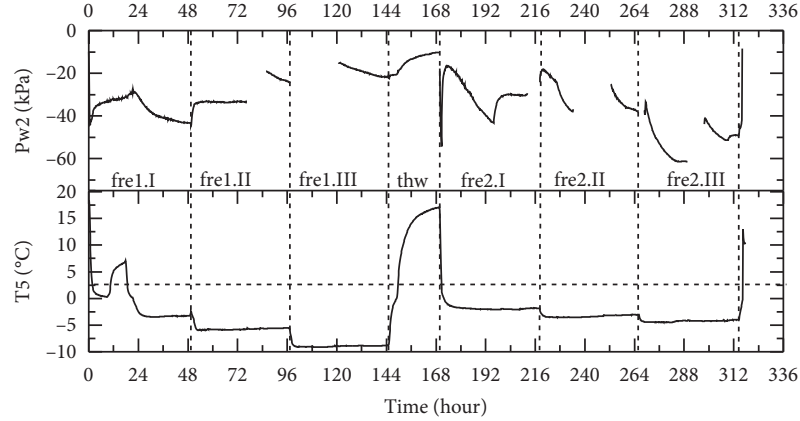

(b)

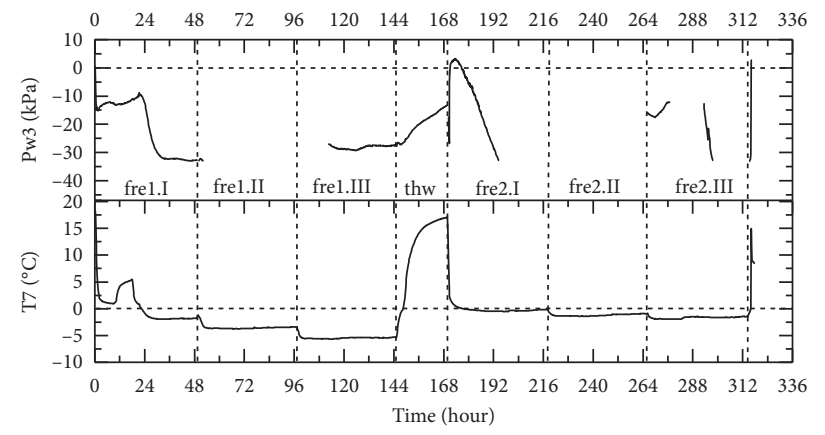

(c)

Figure 6: (a) Variation in the pore water pressure Pw1 and temperature T2 during the freezing and thawing of sample CN2. (b) Variation in the pore water pressure Pw2 and temperature T5 during the freezing and thawing of sample CN2. (c) Variation in the pore water pressure Pw3 and temperature T7 during the freezing and thawing of sample CN2.

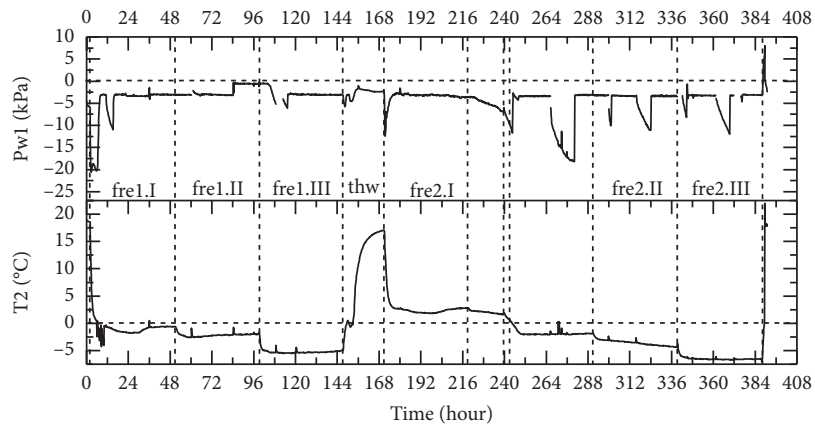

(a)

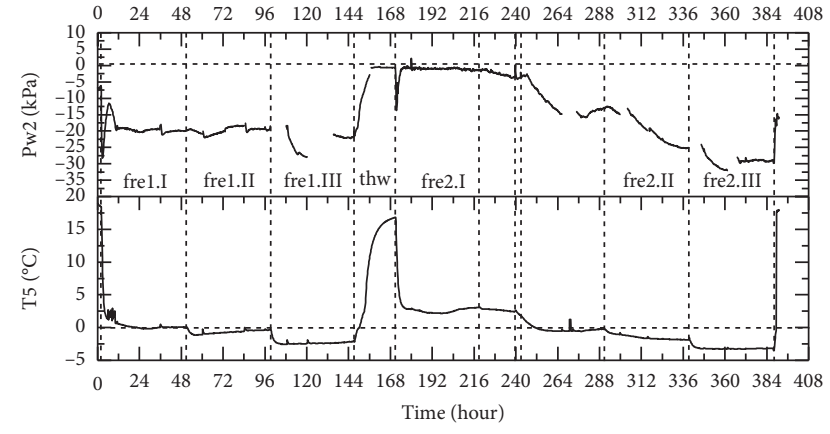

(b)

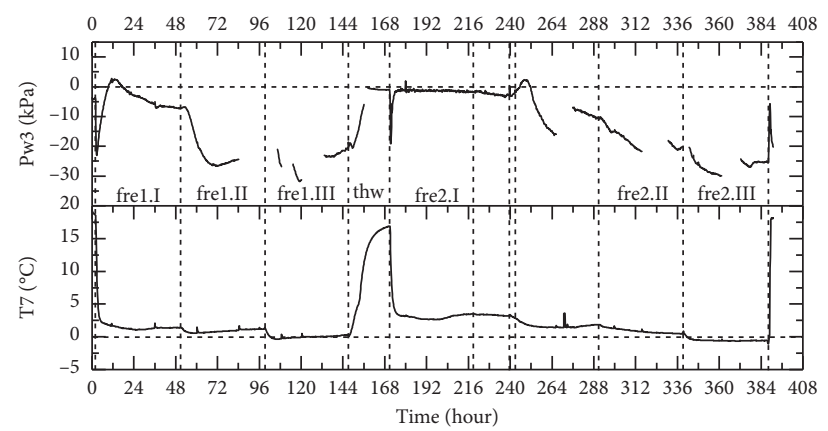

(c)

Figure 7: (a) Variation in the pore water pressure Pw1 and temperature T2 during the freezing and thawing of sample CN3. (b) Variation in the pore water pressure Pw2 and temperature T5 during the freezing and thawing of sample CN3. (c) Variation in the pore water pressure Pw3 and temperature T7 during the freezing and thawing of sample CN3. 


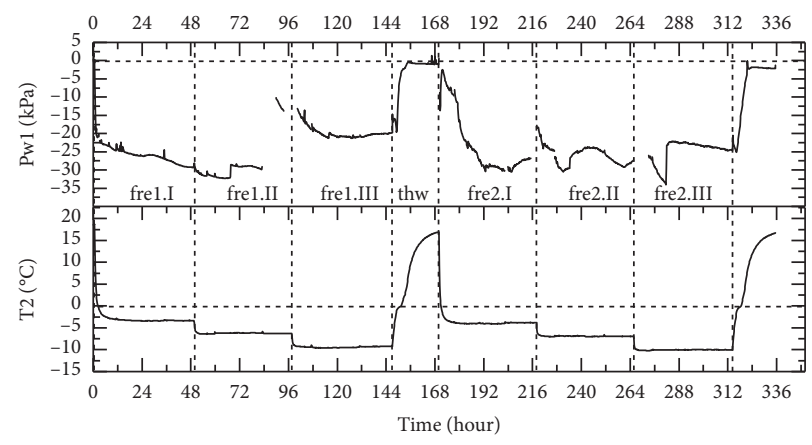

(a)

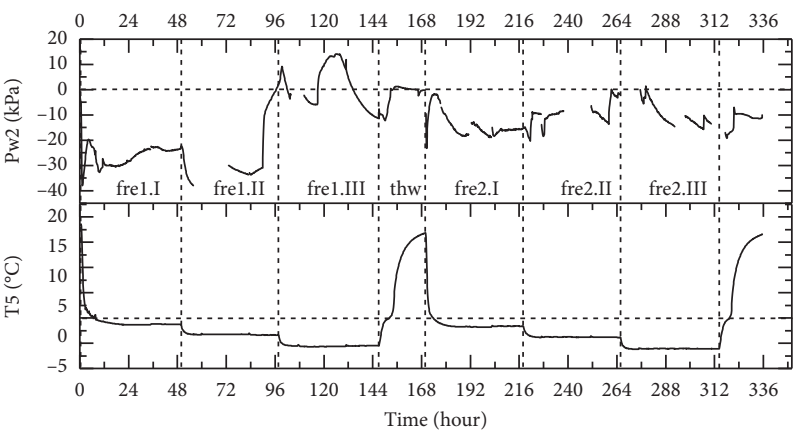

(b)

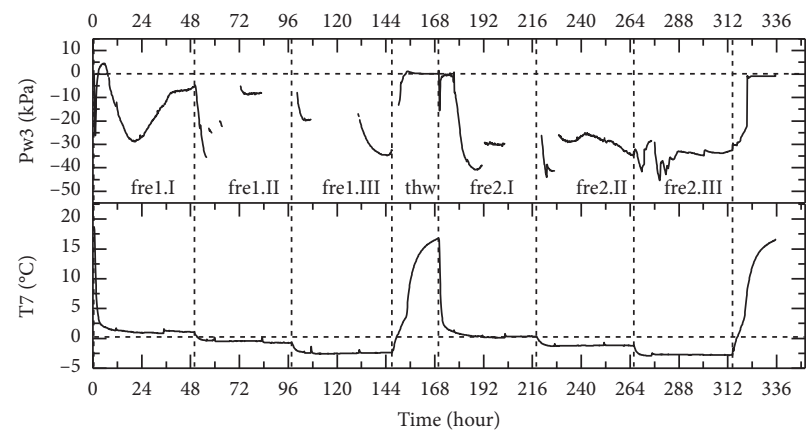

(c)

FIgURE 8: (a) Variation in the pore water pressure Pw1 and temperature T2 during the freezing and thawing of sample CN4. (b) Variation in the pore water pressure Pw2 and temperature T5 during the freezing and thawing of sample CN4. (c) Variation in the pore water pressure Pw3 and temperature T7 during the freezing and thawing of sample CN4.

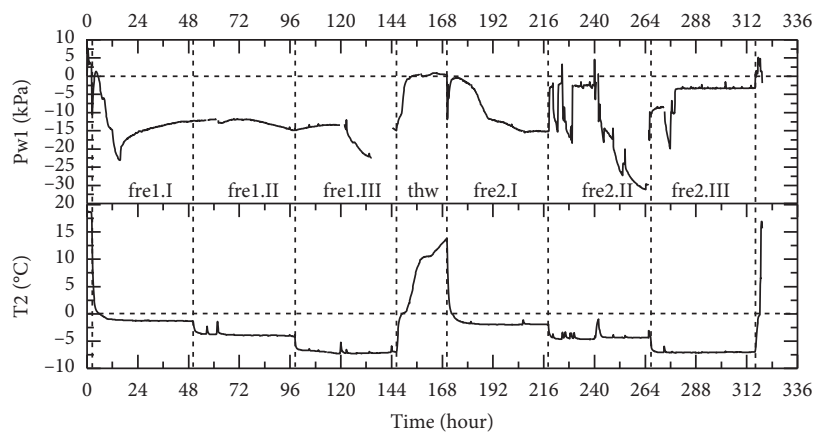

(a)

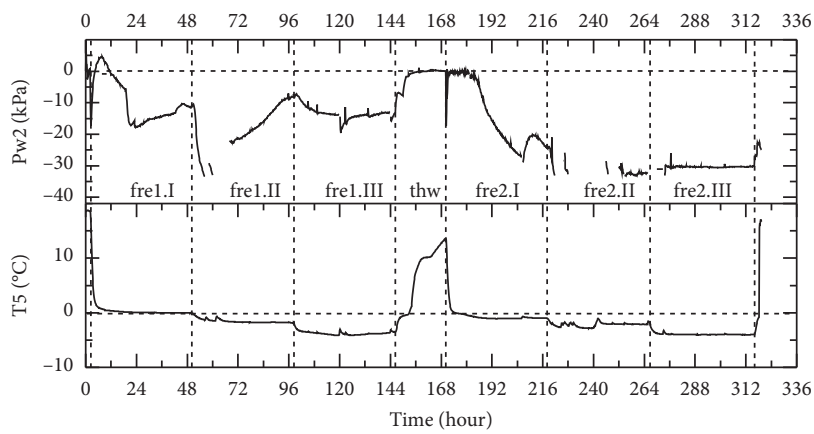

(b)

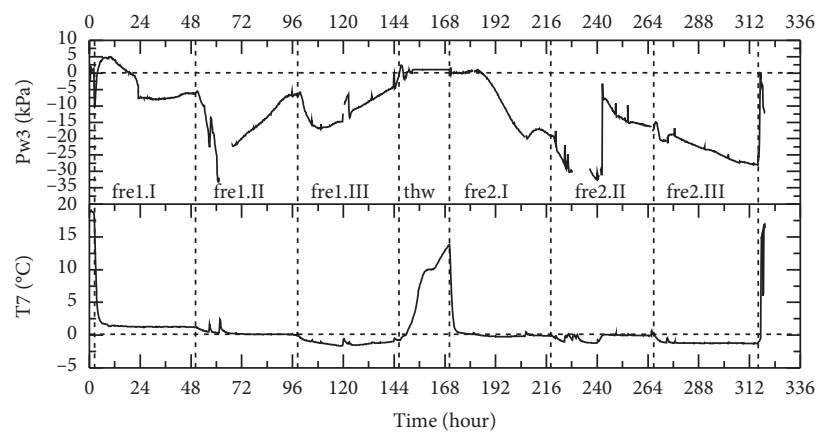

(c)

Figure 9: (a) Variation in the pore water pressure Pw1 and temperature T2 during the freezing and thawing of sample CN5. (b) Variation in the pore water pressure Pw2 and temperature T5 during the freezing and thawing of sample CN5. (c) Variation in the pore water pressure Pw1 and temperature T7 during the freezing and thawing of sample CN5. 
TABLE 3: The minima of pore water pressure during every freezing stage (fre1 and fre2) during tests.

\begin{tabular}{lccccrrr}
\hline & & & \multicolumn{2}{c}{ Fre1 } & \multicolumn{3}{c}{ Fre2 } \\
Samples & Initial water content $\%$ & & \multicolumn{3}{c}{ Minimum of PWP (kPa) } & Pw2 \\
& & Pw1 & Pw2 & Pw3 & Pw1 & -19.07 \\
\hline CN1 & 10.70 & -12.49 & -18.689 & -16.93 & -16.42 & -17.21 \\
CN2 & 18.28 & -14.89 & -44.75 & -32.99 & -17.22 & -61.46 & -33.02 \\
CN3 & 23.98 & -20.5 & -27.99 & -31.72 & -18.22 & -32.00 & -29.33 \\
CN4 & 31.00 & -32.31 & -37.93 & -35.43 & -34.02 & -19.29 & -45.46 \\
CN5 & 37.65 & -23.12 & -33.18 & -33.14 & -31.16 & -33.23 & -32.52 \\
\hline
\end{tabular}

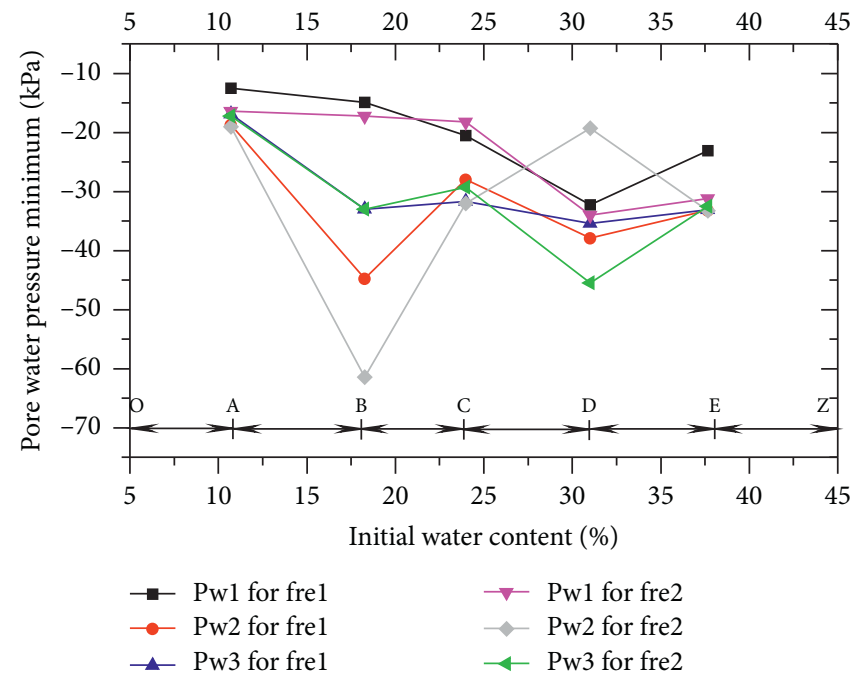

FIGURE 10: Minima of PWP with different initial water contents. $O A, A B, B C, C D, D E$, and $D Z$ correspond to different water content ranges, respectively.

stage (fre1 and fre2) of testing. Figure 10 is the minima of PWP with different initial water contents, which was plotted based on Table 3. For example, as shown in Figure 10, the initial water content of $A, B$, $C$, $D$, and $E$ corresponded to the water contents of being $10.70 \%, 18.28 \%, 23.98 \%, 31.00 \%$, and $37.65 \%$, respectively. The PWP change tendencies differed greatly in the different water content ranges, decreasing in the range of $A B$ and $C D$, increasing in the range of $B C$ and $D E$. This implied that soil water has different free energy states in different ranges of water content. For the sake of analysis, water content is divided into six ranges, including $O A, A B, B C, C D$, $D E$, and $D Z$.

\section{Influence Factor of PWP}

Change of PWP upon freezing is affected by temperature, pressure, soil type, air, ice content, water content, water supply condition, salinity, supercooling, and others [23, 24]. Based on PWP measurements of silty clay, we gave a detailed discussion on some key influencing factors of PWP.

4.1. Influence of Temperature on PWP. If the PWP variations over time were related to temperature changes over time in the same depth of the soil sample, a temperature dependence of the PWP could be established. As shown in Figure 11, the PWP with temperature generally experienced a change mode including three phases. In the first phase, the PWP generally had a slight increasing as the temperature decreased. In the second phase, the PWP had a fast drop as the temperature decreased. In the third phase, the PWP slightly increased as the temperature decreased. Using the PWP Pw2 of sample CN5 in the fre1.I step as an example (Figure 11), at first, the PWP had a slight increase of approximately $5 \mathrm{kPa}$ and then decreased to a minimum $-20.0 \mathrm{kPa}$ as the temperature decreased; finally, it increased slightly as the temperature decreased.

When the soils experienced a further second or third freezing step, the soils still experienced a similar change mode as described in the first freezing step above when the temperature had a sudden drop. The PWP decreased to an extreme point and then increased slightly with decreasing temperature. Using the PWP Pw2 of sample CN5 in the fre1.II step as an example (Figure 11), at first, the PWP remained approximately $-11.5 \mathrm{kPa}$, then decreased to a minimum $-32.8 \mathrm{kPa}$ as the temperature decreased, and finally increased slightly as the temperature decreased.

However, we must realize that the PWP change with temperature is actually a combined effect of all influence factors, not depending only on temperature. Based on phase equilibrium, the PWP change is generally described by GCCE as follows: 


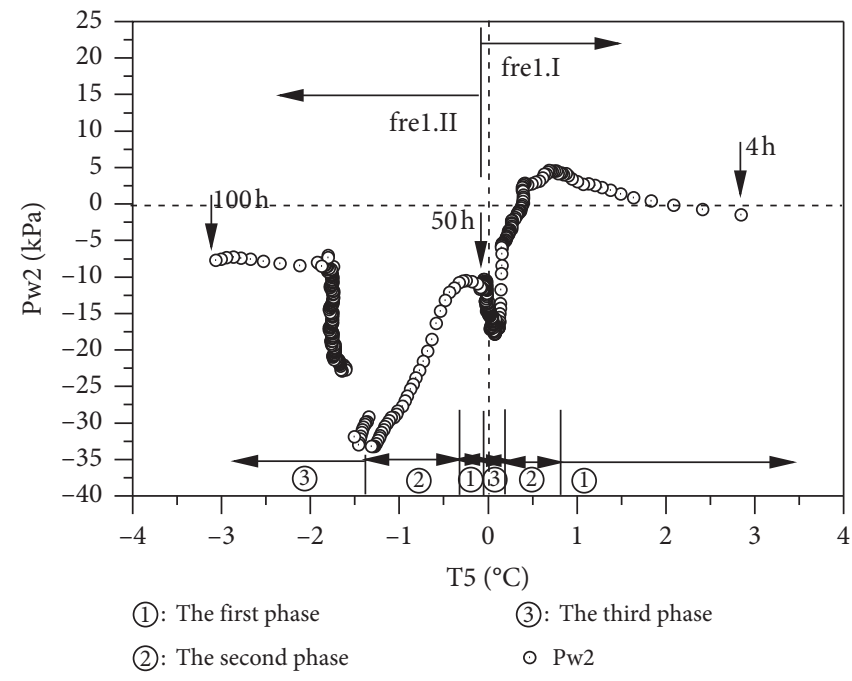

Figure 11: The PWP Pw2 of sample CN5 with temperature during two freezing steps (fre1.I and fre1.II).

$$
\frac{u_{w}}{\rho_{w}}-\frac{u_{i}}{\rho_{i}}=L \frac{T-T_{f}}{T_{f}} ; \quad T_{s} \leq T \leq T_{f},
$$

where $L$ is the latent heat of fusion; $T_{f}$ is the freezing point of water; $T$ is the temperature of the ice and water; $\rho_{w}$ and $\rho_{i}$ are the densities of water and ice, respectively; $u_{w}$ and $u_{i}$ is the gauge pressure of water and ice; and $T_{s}$ is the ice segregation temperature. The PWP change depends only on the temperature, irrespective of ice pressure. However, soil freezing may be more inclined to be a nonequilibrium (irreversible) thermodynamic process [23], and thus the PWP change should have some time effect, which needs further research.

4.2. Influence of Ice Pressure on PWP. In a range of high water content (DE), irrespective of ice-water phase transition, ice skeleton begins to form and bear the vast majority of load as the water content increases, ice pressure increases based on effective stress principle, and thus the PWP increases. In addition, as the water content increases, the strength of ice skeleton increases, and part of unfrozen water is confined in the occluded space by ice. When there occurs the ice-water phase change in soils, a larger ice pressure occurs because of a larger density of water than ice. The PWP increases as ice pressure increases, based on the GCCE (1).

Based on the effects above, we suggested that the PWP induced by ice pressure increases as water content increases in the range of high water content (DE), especially when the unfrozen water is confined in the occluded space by ice. For example, as shown in Figure 9(b), during the freezing stage (frel.III) of sample CN4, although the temperature T5 is subzero, the maximum of PWP Pw2 reached $15 \mathrm{kPa}$. The high PWP may be ascribed to the fact that the PWP probe is confined in an occluded space by ice. Therefore, the PWP has a fast increase because of ice-water phase change.

4.3. Influence of Soil Type on PWP. Compared to the results of sandy soil that are referred to by Zhang et al. [22], silty clay differs greatly from sandy soil in the change characteristic of PWP as follows:

(1) The PWP drop of silty clay is larger than that of sandy soil during the freezing, which may be ascribed to the differences in particle size composition, pore size, surface energy, permeability, specific surface area, etc.

(2) In the early stage of freezing, silty clay has a slight increase in PWP, while sandy soil remains constant. The difference implied that soil water of silty clay is more susceptible to pressure, compared to sandy soil. The differences in the PWP may result from a combination of two factors. First, the PWP in the sandy soil sample has a faster dissipation rate than the PWP in the silty clay sample because of the higher permeability of sandy soil. Second, silty clay may have a more significant increase in frost heaving stress than the sandy soil during freezing.

(3) In silty clay, the PWP at a position can be affected by the PWP at its adjacent position, while in sandy soil, the PWP at a position is not affected by the PWP at its adjacent position. This may be ascribed to two factors: one is that the permeability of sandy soil is larger than silty clay; the other is that more unfrozen water content of silty clay than sandy soil favors building a connected path for water migration.

(4) The PWP of sandy soil has a different change mode between the first- (fre1) and the second- (fre2) step freezing (i.e., before and after the freeze-thaw process). This implies that the physical and mechanical properties of sandy soil experience a significant change after freeze-thaw cycles. However, the PWP of silty clay has not a different change mode between the first- (fre1) and the second- (fre2) step freezing. This may be because the number of freeze-thaw cycles is so small (one freeze-thaw cycle) to induce a significant change in the physical and mechanical properties of silty clay. 
In addition, ice material also can bear load and absorb water as soil does, and thus ice can be regarded as a special type of soil, in some sense.

4.4. Influence of Air on PWP. In unsaturated soil, the total soil suction is composed of matric and osmotic suctions, which can be presented as follows:

$$
\psi=\left(u_{a}-u_{w}\right)+\pi
$$

where $\psi$ is the total soil suction; $\left(u_{a}-u_{w}\right)$ is the matric suction; $u_{a}$ is the pore air pressure; and $\pi$ is the osmotic suction. The osmotic suction depends on the solute concentration. The item on the osmotic suction is ignored because no or little salinity exists in the soil tested, and thus the total soil suction is presented as follows:

$$
\psi=\left(u_{a}-u_{w}\right)
$$

In addition, in terms of the partial vapor pressure of soil water, the total soil suction can be presented as follows (Richards, 1965):

$$
\psi=-\frac{R T}{v_{w 0} \omega_{v}} \ln \left(\frac{\bar{u}_{v}}{\bar{u}_{v 0}}\right),
$$

where $R$ is the molar gas constant; $T$ is the absolute temperature; $v_{w 0}$ is the specific volume of water; $\omega_{v}$ is the molecular mass of water vapor; $\bar{u}_{v}$ is the partial pressure of pore water vapor; and $\bar{u}_{v 0}$ is the saturation pressure of water vapor over a flat surface of pure water at the same temperature. Based on equations (3) and (4), we can present the PWP as follows:

$$
u_{w}=u_{a}-\frac{R T}{v_{w 0} \omega_{v}} \ln \left(\frac{\bar{u}_{v}}{\bar{u}_{v 0}}\right) .
$$

When the water content of sample is low, the axistranslation technique is generally used to measure the soilwater characteristic curve; a high air pressure is generally applied. The air pressure has a further sharp increase as water content further decreases, and thus, the first item on the right side of equation (5) is larger, while the total soil suction has a logarithmic relationship with the partial pressure of pore water vapor, based on equation (4). Therefore, when the water content is low, the second item of equation (5) is also relatively larger. Based on a combined effect of the first and second items, in a range of low water content (OA), the PWP change is little as water content change.

4.5. Influence of Water Content on PWP. The PWP change depends on water content. During soil freezing, PWPs in samples with low water content were less sensitive to the temperature change, while PWPs in samples with larger water content were sensitive to the temperature change. When water content of soil sample is low, the phase transitions between ice, water, and vapor are nearly stopped. Therefore, the change of PWP with temperature is less sensitive. However, when water content of soil sample is larger, the phase transition between ice and water is very significant. Therefore, the PWP change with temperature is sensitive.

\section{Analysis on Influence Factor of PWP}

The "w-shaped double-valley" characteristic in PWP is actually a response of soil water energy state to varied factors, which is a combined effect from temperature, pressure, salinity, matric potential, ice content, air, etc. We can describe this relationship as followss:

$$
\Delta P_{w f}=\Delta P_{w T}+\Delta P_{w p}+\Delta P_{w c}+\Delta P_{w s}+\Delta P_{w i}+\Delta P_{w G},
$$

where $\Delta P_{w f}$ is the total PWP change; $\Delta P_{w T}$ is the PWP change induced by the temperature gradient when the soil sample is saturated; $\Delta P_{w P}$ is the PWP change that is influenced by the internal stress changes of the soil (which involves the changes of external load and frost heaving stress or ice pressure); $\Delta P_{w c}$ is the PWP change induced by the solute concentration; $\Delta P_{w s}$ is the PWP change induced by the soil matrix, i.e., matric potential; $\Delta P_{w \mathrm{i}}$ is the PWP change induced by the ice matrix; and $\Delta P_{w G}$ is the PWP change induced by air.

Figure 12 is the influence-factor decoupling analysis on PWP with initial water content, which is described based on equation (6). Refer to Section 4.1, $\Delta P_{w T}$ mainly depends on the temperature in the temperature ranges of phase transition and thus nearly remains constant with water content increasing. $\Delta P_{w c}$ remains zero or a slight depression because no or little salinity exists in the soil tested. In the range of low water content, as initial water content increases, the matric suction decreases and thus $\Delta P_{w s}$ increases. As initial water content increases, ice content and its specific surface area increase, and ice skeleton forms. The matric suction of ice skeleton increases and thus $\Delta P_{w i}$ decreases. When initial water content is low, almost all of pores remain connect and are full of air, and thus PWP is mainly affected by air pressure. Therefore, $\Delta P_{w G}$ decreases as air content decreases. When initial water content is high, almost all of pores remain connect and are full of ice, and the unfrozen water is generally confined in a closed space. Therefore, $\Delta P_{w P}$ increases because of volume increasing induced by ice-water phase change as water content increases in the ranges of high water content.

Based on influence-factor analysis method, we can present a reasonable interpretation to the "w-shaped double-valley" characteristic of PWP. The PWP valley V1 is ascribed to a combined effect of $\Delta P_{w G}$ and $\Delta P_{w s}$. Both of them intersect at point $A$. When the initial water content is smaller than point $A$, the drop rate of $\Delta P_{w G}$ is larger than the increase rate of $\Delta P_{w s}$; when the initial water content is larger than point $A$, the drop rate of $\Delta P_{w G}$ is smaller than the increase rate of $\Delta P_{w s}$. Therefore, there exists a minimum of PWP in point A. Similarly, the PWP valley V2 is ascribed to the combined effects of $\Delta P_{w i}$ and $\Delta P_{w P}$. Both of them intersect at point $B$. When the initial water content is smaller than point $\mathrm{B}$, the drop rate of $\Delta P_{w i}$ is larger than the increase rate of $\Delta P_{w P}$; when 


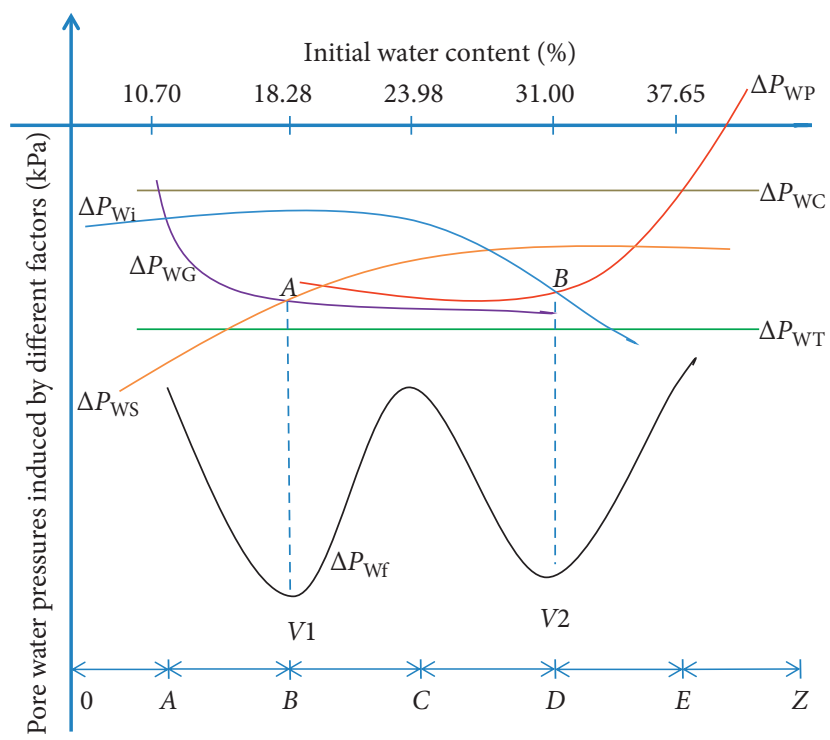

FIGURE 12: Influence-factor analysis of PWP with initial water content. $O A, A B, B C, C D, D E$, and $D Z$ correspond to different water content ranges, respectively.

the initial water content is larger than point $\mathrm{A}$, the drop rate of $\Delta P_{w i}$ is smaller than the increase rate of $\Delta P_{w P}$. Therefore, there exists a minimum of PWP at point $\mathrm{B}$.

The different PWP is commonly referred to as the free energy state of soil water, which refers to the content and energy of free water, capillary water, weakly bound water, strongly bound water, and interfaces between ice, water, and air. In addition, the soil water state is closely related to the pore morphology, mineral composition, and grain size composition. These issues all need a further detailed research.

\section{Discussion on the Tensiometer Method for PWP Measurement in Frozen Soil}

Using tensiometer method, we found that PWP had a drop during soil freezing and increased during soil thawing. Therefore, a reasonable change tendency in PWP can be measured using this method, which indicated that the method is valid. However, there still exist some limitations in the method, which is mainly embodied in the following four disadvantages:

(1) Cavitation occurs in the inner liquid of probe lead to measurement failure. For example, as shown in Figures 5-9, the discontinuity of data is mainly ascribed to the measurement failure induced by cavitation occurring in the inner liquid of probe. This problem is always a challenge for design of this kind of probe. To avoid cavitation occurring and obtain consistent and valid data, the probe must be reasonably saturated before testing.

(2) The porous ceramic cup is relatively smaller in strength, easy to fracture when subjected to high stress. Therefore, the probe is not suitable to apply under high stress condition. During soil freezing, a high frost heaving stress occurs in the soil because of frost heave. A high stress also can occur in the soil under heavy external load. The high stress frequently makes the probe fracture and failure.

(3) The PWP has generally a broad change range (from $-100 \mathrm{kPa}$ to several megapascals) during soil freezing under heavy load. Therefore, the positive measuring range is much larger than the negative measuring range, and the significant difference between positive and negative measuring range will impose restrictions on the accuracy of probe.

(4) It is always questioned whether or not the PWP of frozen soil with low water content can be measured. The method is based on a thermodynamic equilibrium between liquid in the sensor and unfrozen water film in the soil. However, the unfrozen water is relatively less and has a poor fluidity in the frozen soil with low water content. This low water content will cut off the connection of water film and further destroy the thermodynamic equilibrium required by the probe.

In conclusion, a more detailed investigation on the method will be performed to measure the PWP of soils subjected to negative temperature and high stress.

\section{Conclusions}

The following conclusions can be obtained from the PWP measurement of silty clay subjected to freezing and thawing:

During soil freezing, as temperature decreases, PWP first has a slight increase, then decreases to a minimum, and finally has a slight increase. During soil thawing, PWP increases as temperature increases.

The PWP minimum has a "w-shaped double-valley" characteristic as initial water content increases. 
The PWP changes depend on multifactors. An influence-factor analysis of PWP was proposed and gave a reasonable interpretation on the " $\mathrm{w}$-shaped doublevalley" characteristic of PWP.

The method to measure PWP used in this article is valid for the PWP measurement during soil freezing and thawing. However, there still exist some limitations for further research.

\section{Data Availability}

The data are available from the corresponding author upon request.

\section{Conflicts of Interest}

The authors declare that they have no conflicts of interest regarding the publication of this paper.

\section{Acknowledgments}

The authors would like to thank the Natural Science Foundation of China (no. 41501072) and Department of Transportation of Gansu Province (no. 2017-008) for their financial support.

\section{References}

[1] S. Taber, "Frost heaving," The Journal of Geology, vol. 37, no. 5, pp. 428-461, 1929.

[2] S. Taber, "The mechanics of frost heaving," The Journal of Geology, vol. 38, no. 4, pp. 303-317, 1930.

[3] D. H. Everett, "The thermodynamics of frost damage to porous solids," Transactions of the Faraday Society, vol. 57, pp. 1541-1551, 1961.

[4] D. H. Everett and J. M. Haines, "Capillary properties of some model pore systems with special reference to frost damage," Rilem Bulletin, vol. 27, pp. 31-36, 1965.

[5] L. H. Gold, "A possible force mechanism associated with the freezing of liquids in porous materials," Highway Research Board Bulletin, vol. 168, pp. 65-72, 1957.

[6] R. D. Miller, "Frost heaving in non-colloidal soils," in Proceedings of the 3rd international Conference on Permafrost, pp. 708-713, Alberta, Canada, July 1978.

[7] K. O'neill, "The physics of mathematical frost heave models: a review," Cold Regions Science and Technology, vol. 6, no. 3, pp. 275-291, 1983.

[8] K. O’Neil and R. D. Miller, "Exploration of a rigid ice model of frost heave," Water Resources Research, vol. 21, no. 3, pp. 281-296, 1985.

[9] J.-M. Konrad and N. R. Morgenstern, "A mechanistic theory of ice lens formation in fine-grained soils," Canadian Geotechnical Journal, vol. 17, no. 4, pp. 473-486, 1980.

[10] J.-M. Konrad and N. R. Morgenstern, "The segregation potential of a freezing soil," Canadian Geotechnical Journal, vol. 18, no. 4, pp. 482-491, 1981.

[11] L. Zhang, W. Ma, C. Yang, and S. Dong, "A review and prospect of the thermodynamics of soil subjected to freezing and thawing," Journal of Glaciology and Geocryology, vol. 35, no. 6, pp. 1505-1518, 2013.

[12] K. Watanabe, M. Takeuchi, Y. Osada, and K. Ibata, "Microchilled-mirror hygrometer for measuring water potential in relatively dry and partially frozen soils," Soil Science Society of America Journal, vol. 76, no. 6, 2012.

[13] E. J. Chamberlain, "Overconsolidation effects of ground freezing," Engineering Geology, vol. 18, no. 1-4, pp. 97-110, 1981.

[14] J.-M. Konrad, "Pore water pressure at an ice lens: its measurement and interpretation," Cold Regions Science and Technology, vol. 16, no. 1, pp. 63-74, 1989.

[15] J. T. C. Seto and J.-M. Konrad, "Pore pressure measurements during freezing of an overconsolidated clayey silt," Cold Regions Science and Technology, vol. 22, no. 4, pp. 319-338, 1994.

[16] Z. Wen, T. Zhang, Y. Sheng et al., "Managing ice-rich permafrost exposed during cutting excavation along Qinghai-tibetan railway: experiences and implementation," Engineering Geology, vol. 122, no. 3, pp. 316-327, 2011.

[17] K. D. Eigenbrod, S. Knutsson, and D. C. Sheng, "Pore-water pressures in freezing and thawing fine-grained soils," Journal of Cold Regions Engineering, vol. 10, no. 2, pp. 77-92, 1996.

[18] C. Harris and M. C. Davies, "Pressures recorded during laboratory freezing and thawing of a natural silt-rich soil," in Proceedings of the 7th International Conference on Permafrost Conference, pp. 23-27, Yellowknife, Canada, June 1998.

[19] R. W. McGaw, R. L. Berg, and J. W. Ingersoll, “An investigation of transient processes in an advancing zone of freezing," in Proceedings of the Permafrost: 4th International Conference, pp. 821-825, Washington, DC, USA, July 1983.

[20] Y. Miyata and S. Akagawa, "An experimental study on static soild-liquid phase equilibrium in the pores of a porous medium," Heat Transfer-Japanese Research, vol. 26, no. .2, pp. 69-83, 1997.

[21] Y. Miyata and S. Akagawa, "An experimental study on dynamic soild-liquid phase equilibrium in the pores of a porous medium," JSME International Journal Series B, vol. 41, no. 3, pp. 590-600, 1998.

[22] L. Zhang, W. Ma, C. Yang, and C. Yuan, "Investigation of the pore water pressures of coarse-grained sandy soil during open-system step-freezing and thawing tests," Engineering Geology, vol. 181, pp. 233-248, 2014.

[23] W. Ma, L. Zhang, and C. Yang, "Discussion of the applicability of the generalized Clausius-Clapeyron equation and the frozen fringe process," Earth-Science Reviews, vol. 142, pp. 47-59, 2015.

[24] L. Zhang, W. Ma, C. Yang, Z. Wen, Z. Wen, and S. Dongau, "An investigation of pore water pressure and consolidation phenomenon in the unfrozen zone during soil freezing," Cold Regions Science and Technology, vol. 130, pp. 21-32, 2016. 